\title{
twist and snail as positive and negative regulators during Drosophila mesoderm development
}

\author{
Maria Leptin \\ Max Planck Institut für Entwicklungsbiologie, 7400 Tübingen, Germany
}

\begin{abstract}
twist and snail are members of the helix-loop-helix and zinc-finger protein families, respectively, and determine the development of the mesoderm in Drosophila. This paper analyzes their role in mesoderm development by examining how they affect the expression of downstream genes. twist and snail act by regulating gene expression in the mesoderm and in neighboring regions, and have distinct roles in this process. snail prevents expression in the mesoderm of genes that are destined to be active only in more lateral or dorsal regions. twist is required for the activation of downstream mesodermal genes. twist is also required for the full expression of snail and for the maintenance of its own expression. Only the absence of both twist and snail results in the complete loss of all mesodermal characteristics.
\end{abstract}

[Key Words: twist; snail; mesoderm; Drosophila; helix-loop-helix proteins; embryogenesis]

Received May 20, 1991; revised version accepted June 17, 1991.

The mechanisms by which the mesoderm is determined during early development vary in different species. For example, in vertebrates, soluble factors secreted by nonmesodermal cells induce mesoderm formation /for review, see Slack 1991), whereas in Drosophila, the nuclear concentration of a maternal transcription factor, the dorsal protein, determines mesodermal fate (Rushlow et al. 1989; Steward 1989; Roth et al. 1989). However, early mesoderm-specific genes, such as twist, snail, or MyoD, which are expressed after the initial mesoderm determination and probably regulate further mesoderm development, appear to be remarkably homologous even between insects and vertebrates (Davis et al. 1987; Hopwood et al. 1989; Michelson et al. 1990; Paterson et al. 1991; Wolf et al. 1991; A. Nieto and D.G. Wilkinson, pers. comm.). This suggests that once the mesoderm is determined, different species use similar regulatory molecules to govern its further development.

In Drosophila, the mesoderm arises from the ventral region of the embryo. A group of maternal genes, the dorsal group genes and cactus, define positional values along the dorsoventral axis of the embryo by the nuclear concentration of the dorsal gene product (Roth et al. 1989; Rushlow et al. 1989; Steward 1989). The dorsal nuclear protein directly or indirectly regulates the activation or repression of zygotic genes. Differences in the expression of zygotic genes along the dorsoventral axis are visible as early as $2 \mathrm{hr}$ after fertilization, which is $\sim 1$ $\mathrm{hr}$ before the invagination of the mesoderm begins. At least four domains along the dorsoventral axis can be distinguished by their fates and their gene-expression patterns. The region next to the mesoderm is occupied by the ventral ectoderm, followed more dorsally by the dorsolateral ectoderm and, finally, by the amnioserosa.

Two zygotic genes, twist and snail, are known to be required for the formation of the mesoderm (NüssleinVolhard et al. 1984). Embryos mutant in these genes gastrulate abnormally, form no mesodermal germ layer or mesodermal derivatives, and die at the end of embryogenesis (Simpson 1983; Grau et al. 1984). The lateral and dorsal parts of the embryo are not affected in the mutants. The products of the twist and snail genes are members of the helix-loop-helix and zinc-finger protein families, respectively (Boulay et al. 1987; Thisse et al. 1988 ) and are therefore probably involved in transcriptional regulation. They are expressed in the mesoderm anlage (Thisse et al. 1988; Leptin and Grunewald 1990). Their structure and expression patterns, and the mutant phenotypes suggest that twist and snail play a role in determining the differentiation and morphogenesis of the mesoderm, probably by regulating the transcription of other genes.

Although neither twist nor snail mutant embryos develop a mesoderm, their phenotypes are different (Leptin and Grunewald 1990). In twist mutants, the ventral furrow (the early invagination of the mesoderm) is only half the width of the wild-type furrow, suggesting that the mesoderm anlage might be narrower than in the wildtype embryo. In snail mutants, which make no furrow, the ventral epithelium buckles irregularly over the normal width of the mesoderm anlage. The phenotype of embryos mutant for both genes is much stronger than that of either single mutant alone; the ventral epithelium is indistinguishable from the neighboring ecto- 
derm. This indicates that twist and snail do not act exclusively in the same pathway but have at least partly independent functions. Because they act most likely as transcriptional regulators, we tested their roles in mesoderm development by examining their effects on the expression of a number of genes normally expressed in the mesoderm and at its borders. As representative examples, we used PS $2 \alpha$, expressed in the mesoderm (Bogaert et al. 1987); single-minded (sim), expressed in mesectodermal cells that lie at the border of the mesoderm (Crews et al. 1988) and do not contribute to the mesoderm, but become part of the nervous system (CamposOrtega and Hartenstein 1985|; and crumbs, expressed outside the mesoderm, in the ventral and more dorsal ectoderm (Knust et al. 1987). These genes are required for the proper development of the cells in which they are expressed, [i.e., for the differentiation of mesectodermal cells $(\operatorname{sim})$, the attachment of mesodermal cells to the ectoderm (PS2 $\alpha$ ), and for the organization of the epidermis (crumbs)]. Under the control of twist and snail, respectively, these genes are activated in or their expression is confined to the areas in which they are destined to be active.

\section{Results}

\section{Expression patterns of twist and snail}

Because the temporal and spatial limits of twist and snail expression are important for this study, they were analyzed and compared in detail.

As reported previously (Thisse et al. 1988; Leptin and Grunewald 1990), both twist and snail RNA are expressed in the prospective mesoderm at the cellular blastoderm stage (Fig. 1A,B). However, when first detectable (during nuclear cycle 12), they appear in a diffuse band only half the width of the prospective mesoderm (Fig. $1 \mathrm{C}, \mathrm{D})$.

The expression patterns of $t$ wist and snail differ in a number of aspects. Along the anterior-posterior axis, twist RNA and protein extend farther anterior and posterior than snail RNA and protein (Fig. 2A-D). snail RNA and protein form a sharp posterior boundary (Fig. 2B,D). [snail protein like twist (Thisse et al. 1988), is nuclear (Fig. 2J), consistent with the role suggested by the zinc-finger motifs in its sequence.] Although twist continues to be expressed in the mesoderm throughout germ-band extension (Fig. 2E), snail products completely disappear from the mesoderm halfway through germband extension and appear in a subset of cells in the neural ectoderm, which by their distribution and shape are probably neuroblasts (Figs. $2 \mathrm{~F}$ and $6 \mathrm{E}$ ).

The lateral boundaries of $t$ wist and snail expression are not identical. Both snail RNA and protein have a discrete lateral boundary, whereas twist RNA and protein form a gradient at the edge of the prospective mesoderm (Fig. 2G-J). The fainter part of this gradient extends beyond the sharp snail boundary into the territory of the prospective ectoderm. Figure 2 shows this difference at its most extreme point, in mid-cellularization. Much ear-

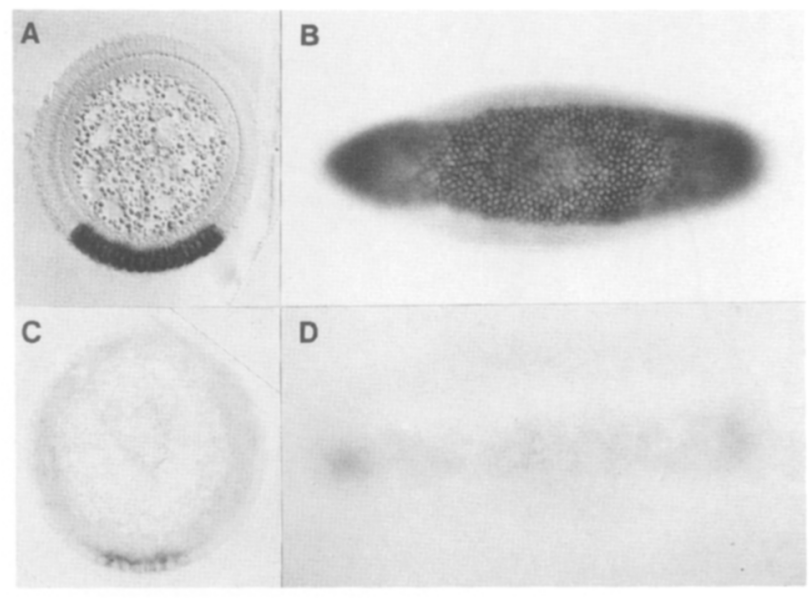

Figure 1. Cellular and early syncytial blastoderm expression patterns of $t$ wist and snail. snail and twist RNA distribution in cellular blastoderm $(A, B)$ and early syncytial blastoderm $(C, D)$ embryos are shown. $A$ and $C$ are transverse sections of embryos hybridized with a snail probe (dorsal side up); $B$ and $D$ are ventral views of embryos hybridized with a twist probe. Apart from the differences shown in Fig. 2, the two genes are expressed in the same patterns.

lier, the snail boundary is slightly more diffuse than shown here, and later, during gastrulation, the twist boundary sharpens.

\section{Expression domains of other genes along the dorsoventral axis}

The expression of a number of genes normally expressed in and around the mesoderm in embryos lacking twist and snail function was examined. The localization of the expression domains of some of these genes relative to each other and relative to twist and snail was established in double-labeling experiments (in cases where the subcellular localization of the RNAs differ; e.g., Fig. 4B) and by comparisons on serial sections. Their expression patterns are summarized in Figure 3. sim is expressed in mesectodermal cells at the border of the mesoderm (Fig. 4A,B; Crews et al. 1988); crumbs is expressed outside the mesoderm, in the ventral and more dorsal ectoderm (Knust et al. 1987; Fig. 4B). Its expression domain includes the mesectodermal cells. PS2 $\alpha$ is expressed in the mesoderm (Fig. 4C; Bogaert et al. 1987); like snail, it is expressed only in the region between the two lines of mesectodermal cells. The snail and PS2 expression domains do not overlap the sim expression domain. In contrast, twist expression is not confined to this region at the blastoderm stage. The sim-expressing cells lie within the region of the graded distribution of $t$ wist protein. Thus, at this stage, low levels of $t$ wist protein are found in mesectodermal and some ectodermal cells. During late germ-band extension, however, twist products disappear from nonmesodermal cells; and when the mesoderm has invaginated fully, the mesectodermal cells no longer express twist (Leptin and 
Grunewald 1990). Other genes expressed in the prospective mesoderm or ectoderm are listed in the legend to Figure 3.

\section{Expression patterns in twist and snail mutants}

In snail embryos, PS2 and twist are activated in the same
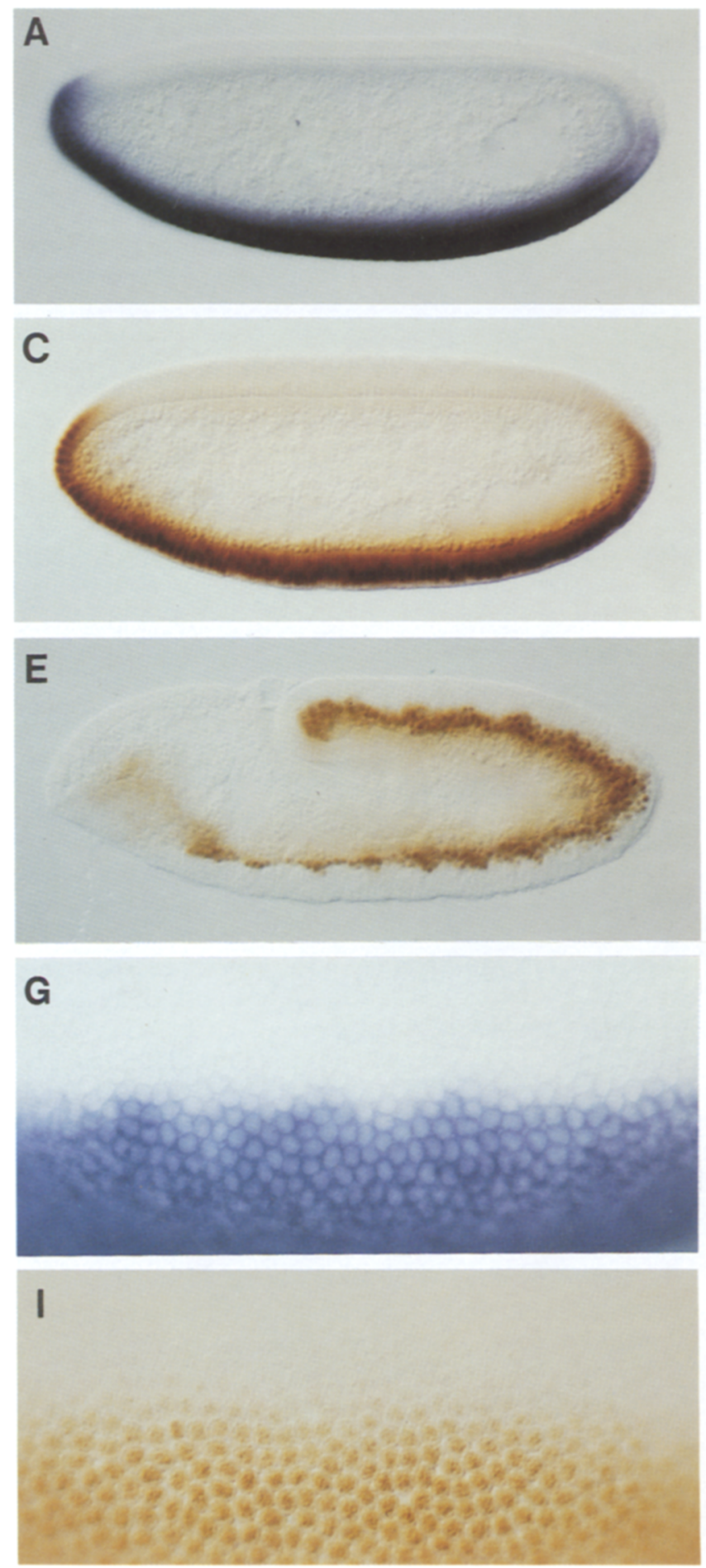

pattern as in the wild type (Fig. 4C,F; Leptin and Grunewald 1990). This is also the case of other early mesodermal genes (see Fig. 4 legend). In contrast, the expression patterns of sim and of ventrolateral genes are altered. crumbs and sim are expressed in the mutant mesoderm [Fig. 4G, $\mathrm{H}_{\text {; for }}$ sim, see also Leptin and Grunewald (1990); Nambu et al. (1990); Rushlow and
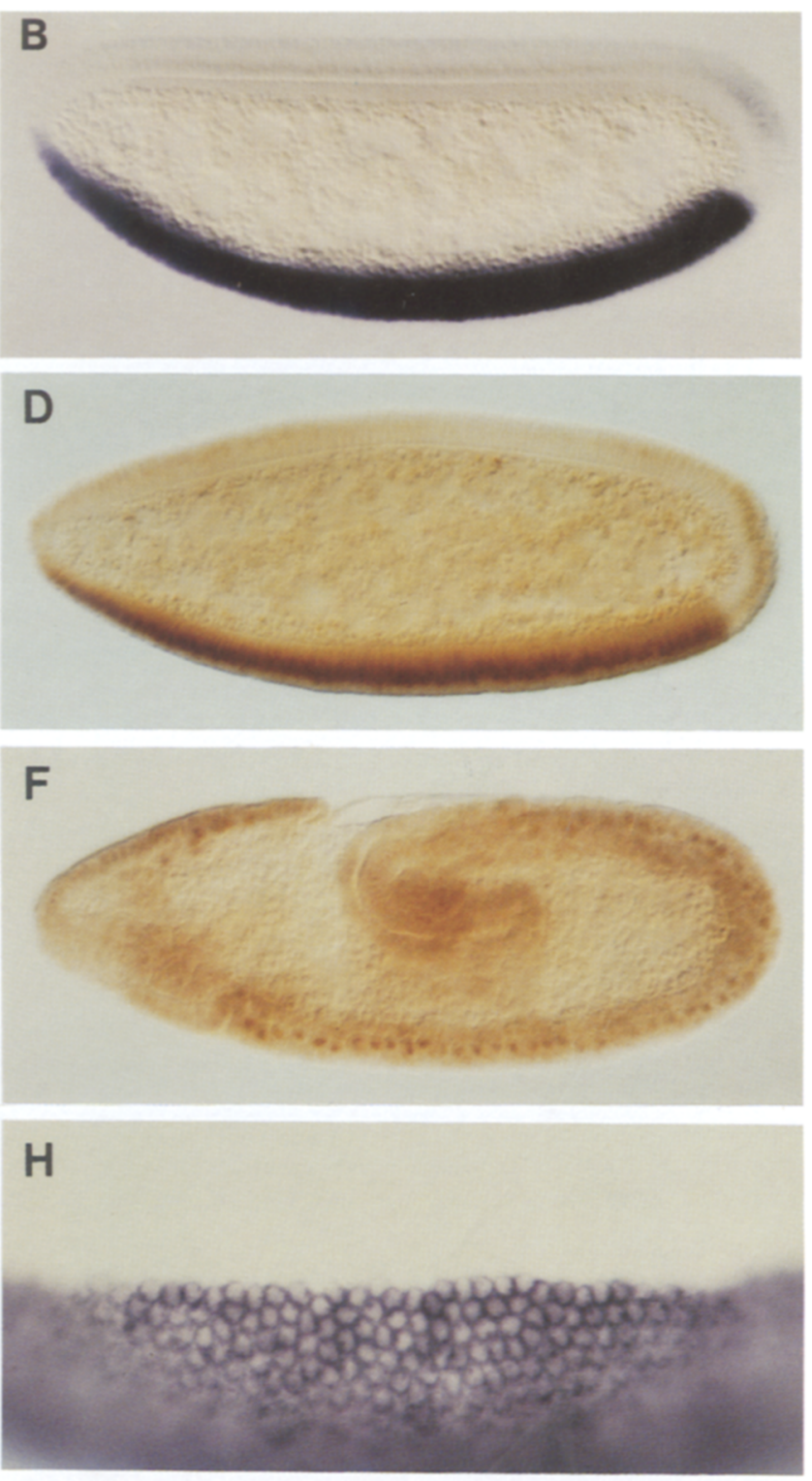

J

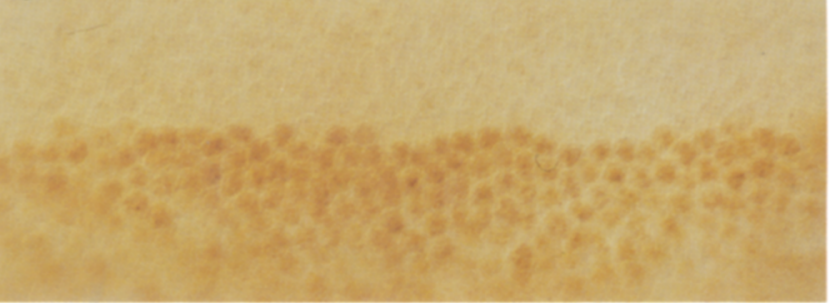

Figure 2. (See facing page for legend.) 


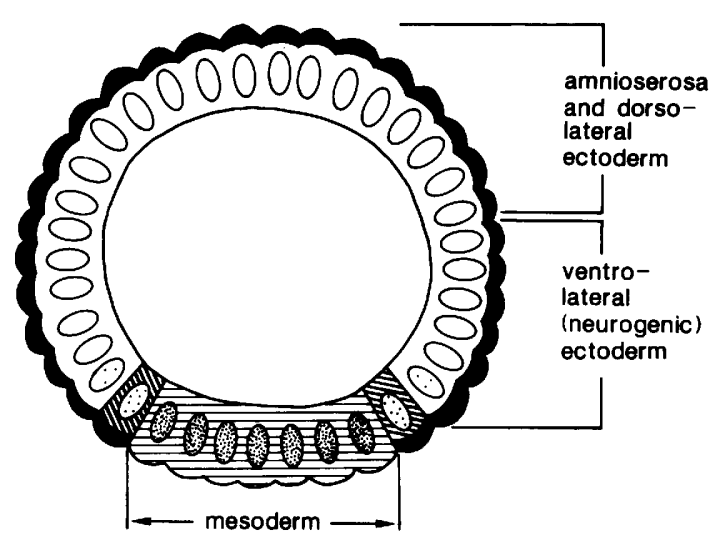

Figure 3. Diagram of zygotic gene expression patterns along the dorsoventral axis. sim $(\mathbb{S}$ ) is expressed in the mesectodermal cells at the edge of the mesoderm. PS2 and snail (目) are expressed in the prospective mesoderm, i.e., the region between the mesectodermal cells. twist (雪) is expressed at high levels in the prospective mesoderm and in lower amounts in mesectodermal and the neighboring ectodermal cells. crumbs $(\square)$ is expressed in the ventrolateral and dorsolateral ectoderm and the prospective amnioserosa. Other genes expressed in the mesoderm at this stage are msh-2 (Bodmer et al. 1990), the early expression of transcript 48 (t48; Gould et al. 1990), and string (Edgar and O'Farrell 1989). Other genes expressed in the ectoderm are Delta (Vässin et al. 1987) and the later t48 (Gould et al. 1990).

Arora (1990)], as are other genes that are normally restricted to more lateral regions [t48 (data not shown); Delta (M. Haenlin and J. Campos-Ortega, pers. comm.); mesectodermal genes ( $\mathrm{Nambu}$ et al. 1990)]. This indicates that snail is not required to activate mesodermal genes, but to repress ventrolateral genes in the mesoderm territory. However, during germ-band extension, twist and PS2 disappear earlier than during wild-type development, suggesting a direct or indirect late role of snail in the maintenance of the expression of these genes (see Discussion).

In twist mutants, the two sim lines lie closer together than in the wild type, at the edge of the region that forms the mutant ventral furrow (Fig. 4D). The crumbs expression domain also extends farther ventrally in twist mutant embryos (Fig. 4B,E), as do those of two other genes expressed in the lateral and dorsal regions at this stage (t48, not shown; Delta, M. Haenlin and J. Campos-Ortega, pers. comm.). Thus, the mutant mesoderm anlage in twist embryos is narrower than in the wild type, consistent with the finding that the ventral furrow in twist embryos is narrower. PS2 is not expressed in these embryos, nor are other genes that are expressed in wild-type mesoderm at this stage (string, B. Edgar, pers. comm.; msh-2, Bodmer et al. 1990; t48, data not shown). Thus, twist is required for the activation of early mesodermal genes but not for the repression of lateral genes.

When both twist and snail function are removed (in twist snail double mutants), no mesodermal or mesectodermal genes are expressed, and the genes of the ventral ectoderm are expressed over the whole ventral surface [data not shown, as crumbs expression in the double mutants looks like Fig. 4H, and PS2 expression looks like Fig. 4F. Double-mutant embryos do not express the sim gene (data not shown; Rushlow and Arora 1990)].

\section{snail and twist expression in twist mutants}

The normal expression pattern of twist protein in snail mutants (Leptin and Grunewald 1990) shows that snail function is neither required for turning on twist expression nor for its early maintenance. Specifically, the width of the mesodermal territory can be defined in the absence of snail.

However, if $t$ wist is required for the expression of all early mesodermal genes, expression of snail and possibly even of twist itself should depend on twist activity. This is indeed the case. snail transcription is never established over the whole mesodermal territory in twist mutant embryos. Its early expression in a narrow band is the same as in the wild type, but it does not become expressed in a wider band (Fig. 5C). Instead, it disappears at the cellular blastoderm, usually by first breaking up into patches (Fig. 5E). Thus, the initial transcription of snail

Figure 2. Differences between twist and snail expression patterns. $(A, C, E, G, I)$ twist expression patterns $(B, D, F, H, J)$; snail expression patterns. $(A, B)$ twist and snail RNA distribution at the cellular blastoderm. $(C, D) t$ twist and snail protein distribution at the cellular blastoderm. The proteins are found in ventral nuclei. snail has a sharp posterior boundary and does not extend around the anterior tip of the embryo. Along the anterior-posterior axis neither twist nor snail is confined to the mesoderm anlage. $(E, F)$ Protein distribution at the fully extended germ-band stage. The mesoderm has invaginated completely and forms a layer of cells on the inside of the ectoderm, clearly visible in $E$, which shows that twist is still expressed in the mesoderm. In contrast, snail is no longer present in the mesoderm but is expressed in neuroblast nuclei (individual brown dots within the ectodermal layer). (G- $I$ ) Views of whole-mount embryos from a ventrolateral angle, focusing on the lateral edge of the mesoderm. $(G, H)$ twist and snail RNA distribution at the mesoderm-ectoderm boundary (during early cellularization). twist $(G)$ is expressed in a gradient, whereas snail has a sharp boundary $(H) .(I, I)$ twist $(I)$ protein, expressed in a gradient and snail $(J)$ protein, with a sharp boundary at the edge of the mesoderm. Note that the snail expression patterns observed with our antibody differ in some details from those published recently by Alberga et al. (1991). We find that (1) the protein appears well before, and not after, gastrulation begins-consistent with the finding that the snail mutant phenotype is visible from the very onset of gastrulation; (2) the protein is never seen only in individual mesodermal cells, but the antibody stains all mesodermal cells homogeneously, as expected, as snail mutations affect all mesodermal cells; (3) the protein is seen only in regions of the embryo that also express the RNA; 4 ) also in neuroblasts, the protein appears to be nuclear and not cytoplasmic. These observations are in agreement with those of Kosman et al. (1991). 
Figure 4. Expression of mesodermal, mesectodermal, and ectodermal genes in wildtype embryos and in twist and snail mutants. $(A, D, G)$ Ventral views of in situ hybridizations of whole-mount embryos at cellular blastoderm; all other panels are transverse sections of embryos during early gastrulation, dorsal side up. In wild-type embryos $(B, C)$, the ventral furrow has begun to form. $(A, D, G) \operatorname{sim}$ is expressed in two lines, each one cell wide, at the edge of the mesoderm. In twist mutants, these lines lie closer together $(D)$; in snail mutants, the gene is expressed over the whole width of the mesodermal territory $(G)$. $(B, E)$ Embryos hybridized simultaneously with probes for sim and crumbs. Because crumbs RNA is localized only in the apical part of each cell and sim is distributed over the whole cytoplasm, their expression domains can be distinguished in sectioned embryos $(B, E)$. In twist embryos, both the sim cells and the edges of the crumbs domain lie farther ventrally and closer to each other than in the wild type. $(H)$ snail mutant embryo hybridized with a crumbs
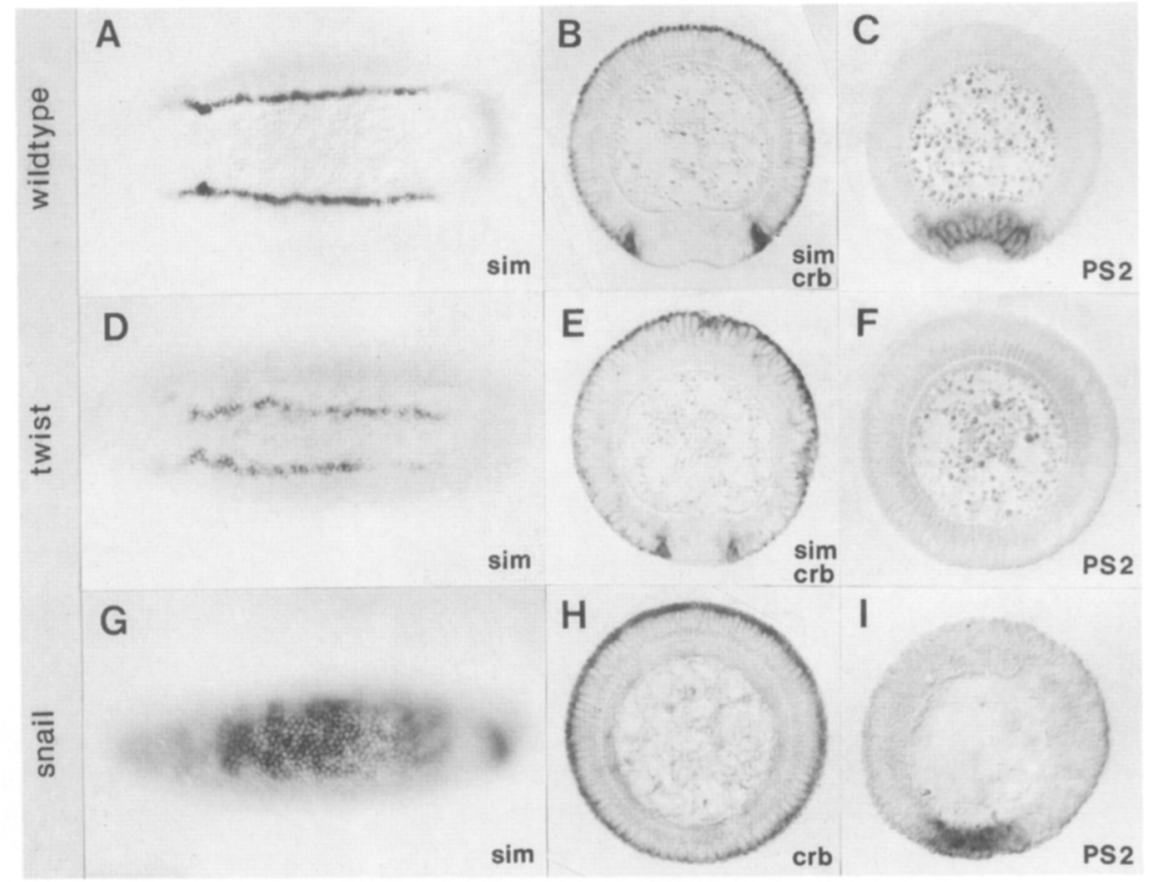
probe. crumbs is expressed around the whole periphery of the embryo. Two other genes expressed in the ectoderm, t48 (Gould et al. 1990) and Delta, show the same changes of expression patterns in the mutants as crumbs (results not shown; $M$. Haenlin and J. Campos-Ortega, pers. comm.). (C, $F, I)$ Embryos hybridized with a PS2 probe. PS2 is not expressed in twist mutants $|F|$ but is expressed normally in snail mutants $(I)$. Other early mesodermal genes that behave in this way are twist, the early ventral expression of 488 (Gould et al. 1990; results not shown), and msh-2 (Bodmer et al. 1990). In embryos mutant for both twist and snail, the crumbs expression pattern looks like that in $H$, and PS2 looks like that in $F$.

in a narrow band is independent of twist, probably directly activated by the maternal genes, but its maintenance and later expression across the whole width of the mesoderm require $t$ wist function. The late expression of snail in neuroblasts is entirely independent of twist (Fig. $6 \mathrm{Fl}$.

twist function appears also to be required for the maintenance of expression of its own RNA. The effects of four strong twist alleles on twist expression were tested. In embryos mutant for any of them, twist RNA is initially transcribed normally, first in a narrow band, then over the whole width of the mesoderm. During cellularization, however, the RNA begins to fade (see Fig. 5D,F) and finally disappears at the beginning of gastrulation (see Fig $5 \mathrm{H}$ ). Thus, the early twist transcription pattern is established, but its expression cannot be maintained in the absence of detectable twist function.

\section{Late fate changes}

Many mesodermal and ventral-ectodermal genes are only expressed during or after germ-band extension, at least 3 $\mathrm{hr}$ later than the genes analyzed above. Late mesodermal genes, such as $\beta_{3}$-tubulin (Leiss et al. 1988; Kimble et al. 1990), pox meso (Bopp et al. 1989), and the embryonic muscle actin Act57A (Tobin et al. 1990) are neither expressed in twist nor in snail mutants (Fig. 6A-D; Leiss et al. 1988|. Although this suggests that snail may have a role in the activation of these genes, it should be noted that in snail mutants, twist also disappears early. Furthermore, even in the wild type, snail disappears from the mesoderm before $\beta 3$-tubulin, pox meso, and Act57A are expressed. Therefore, the failure of snail mutants to express late mesodermal genes is consistent with a direct requirement for twist for the activation of these genes and an indirect role for snail.

The transient expression of snail in twist mutant embryos is not sufficient to repress late ventrolateral genes. The mutant mesodermal region in twist embryos begins to show aspects of ventrolateral behavior after germband extension, in that cells delaminate from it. These cells have the typical shape of delaminating neuroblasts and express genes normally expressed by neuroblasts at this stage (as with hunchback and the late, neuroblastspecific snail; Fig. 6C-E). This suggests that the presence of snail is required continually to repress all lateral characteristics in the mesodermal region.

\section{Discussion}

Together, the results shown here suggest the following early functions for $t$ wist and snail (Fig. 7). twist responds to maternal positional information defining the boundaries of the mesoderm. Within this territory, it is respon- 


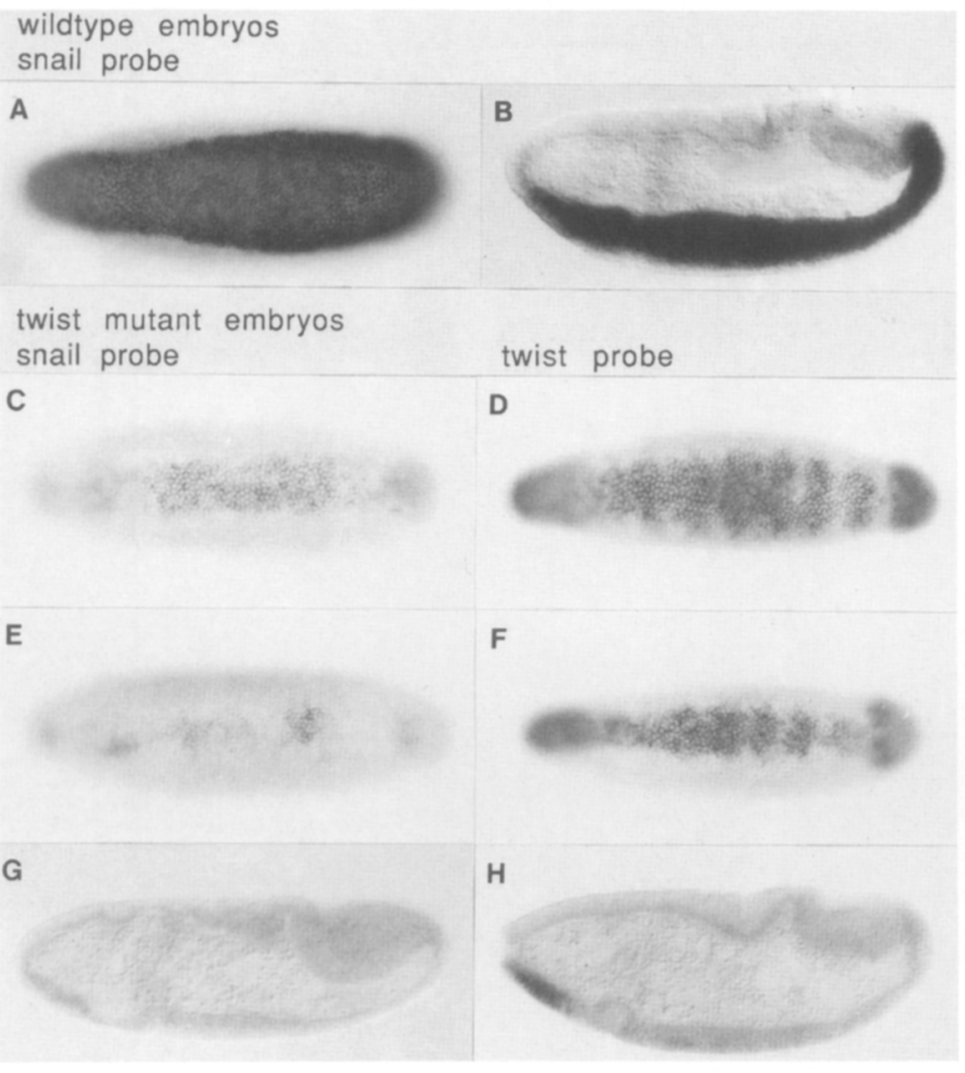

Figure 5. Expression of twist and snail RNA in twist mutants. $(A, B)$ Expression pattern of snail RNA in wild-type embryos at cellular blastoderm $(A$, ventral view) and early gastrulation ( $B$, lateral view). Apart from the differences described in Fig. 1, twist is expressed in the same patterns. $(C-H)$ Expression patterns of snail and twist RNA in twist mutant embryos. $(C, G, E)$ twist mutant embryos [from the nul] allele $\left.\mathrm{Df}(2 \mathrm{R}) \mathrm{twi}^{\mathrm{S}}{ }^{\mathrm{O} \mathrm{O}}\right]$ hybridized with a snail probe. $(D, F, H)$ twist mutant embryos (allele twi ${ }^{\mathrm{IIE}}$ ) hybridized with a twist probe. $(C, D)$ Syncytial blastoderm at the beginning of cellularization (ventral views); $(E, F)$ Cellular blastoderm (ventral views); $(G, H)$ early gastrulation (lateral views). sible for activating and maintaining the expression of early mesoderm-specific genes, including itself and snail. The expression patterns of mesodermal genes in snail mutants show that twist can perform this function in the absence of snail. snail represses genes in the mesodermal territory that are destined to be active only in more lateral or dorsal regions. snail, too, can perform its function alone, as in twist mutants lateral genes are off in the region where snail is expressed early. The comparison of twist and snail twist double mutants shows that the early snail expression has an effect on downstream genes. Because a narrow ventral band of cells differs from lateral cells in behavior and gene expression patterns in twist, but not in the double mutant, and as the only difference between $t$ wist and the double mutant is the early presence of snail RNA, it must be the function of this early snail RNA that makes the twist phenotype different from the double-mutant phenotype. Therefore, the narrow band of snail, itself, represses lateral genes in the mutant mesodermal region in twist embryos.

The combined presence of both twist and snail is required to achieve both activation of mesodermal and repression of lateral genes, and proper development of the mesoderm. Thus, neither gene is sufficient to regulate the whole repertoire of gene expression required to allow mesoderm development, but each alone can regulate the expression patterns of some genes. Only in the absence of both twist and snail do all mesodermal qualities dis- appear from the ventral region of the embryo. This situation also resembles that of dorsal fate determination, where the function of zygotic dorsal-specific genes appears to be to repress lateral fates and allow the expression of dorsal fates (Irish and Gelbart 1987). Thus, in the absence of any region-specific dorsoventral zygotic gene activity the ground state of the blastoderm appears to be the expression of neural ectoderm fates.

This model for the roles of twist and snail as mesoderm gene activators and lateral gene repressors, respectively, is necessarily preliminary. It is possible that mesodermal or lateral genes might be discovered that do not obey the rules described for the genes analyzed here. Furthermore, interactions between genes might complicate the interpretation of mutant expression patterns. For example, a gene under negative control of lateral genes (which are repressed ventrally by snail) would be expressed in the mesoderm but depend on snail for its expression. It is also not possible to distinguish whether the disappearance of twist in snail mutants indicates that snail is normally directly reponsible for the maintenance of twist expression, or whether the disappearance is due to effects of ventrolateral genes normally repressed by snail. The latter seems more likely. First, snail protein itself disappears from the mesoderm during germ-band extension in the wild type, and it is therefore difficult to see how it could be directly responsible for the late maintenance of twist expression. Second, even during wild-type development, twist disappears from 
Figure 6. Expression of late mesodermal and neuroblast markers in mutants. $(A, B)$ Lateral views of extended germ-band wildtype $(A)$ and snail embryo $(B)$ stained with antibodies against the pox meso product (Bopp et al. 1989). $(C, D)$ Lateral views of extended germ-band wild-type $|C|$ and snail $(D)$ embryo hybridized with a probe for the muscle actin gene Act57A. $\mid E-G\}$ Sections through extended germ-band wild-type $(E)$ and twist $(F, G)$ embryos. $E$ and $F$ were hybridized with a snail probe; $G$ was stained with anti-hunchback antibodies. The tracings beneath the sections highlight the mesoderm in the wild type (hatched), the stained neuroblasts (stippled), and the mesectoderm cells at the edge of the mesoderm [(solid) inferred from previous experiments (Leptin and Grunewald 1990/l. (mes) Mesoderm. Arrows indicate neuroblasts delaminating

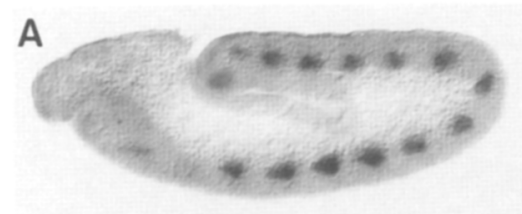

C

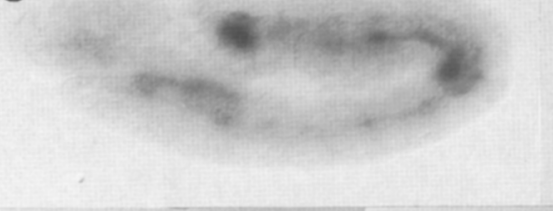

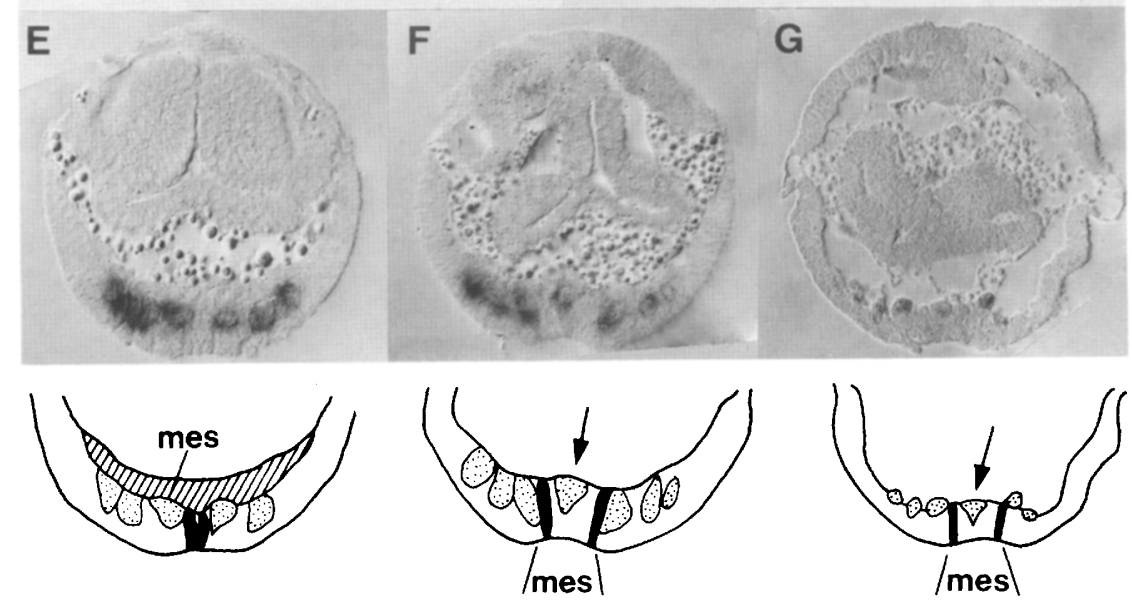

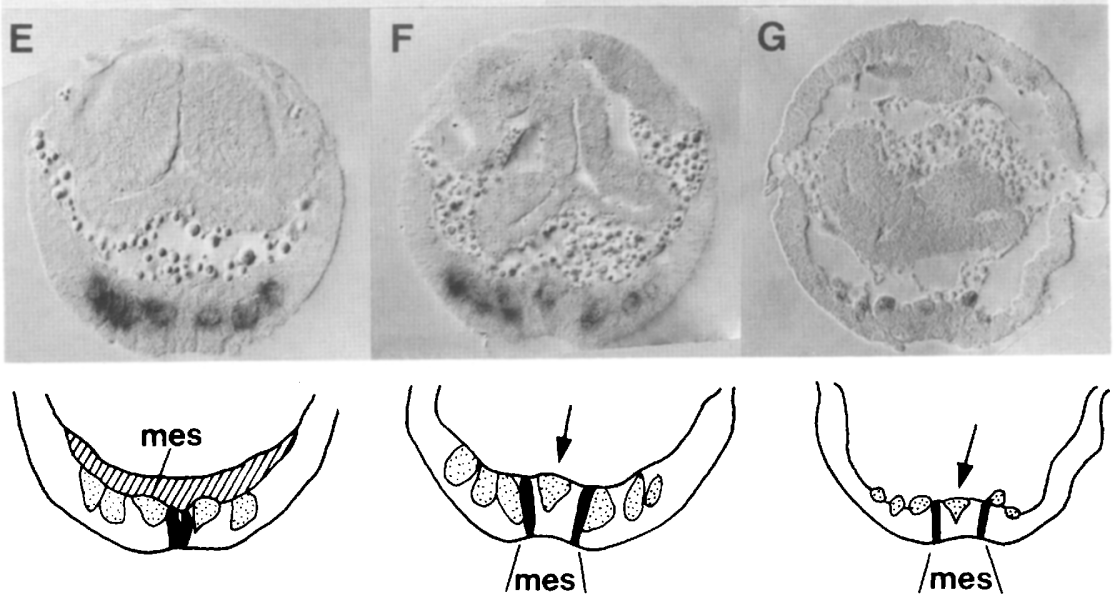

B

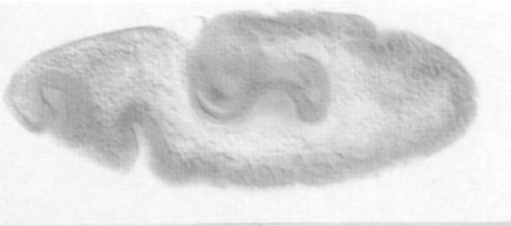

D cells expressing sim and ventrolateral genes (i.e., from mesectoderm cells) during germ-band extension (Leptin and Grunewald 1990). At this time, therefore, it is possible that genes active in this region repress or destabilize twist, which they would also do over the whole mesodermal region in snail mutants.

The transformation of the twist mutant mesoderm into something resembling neural ectoderm is interesting with respect to neuroblast differentiation. The mutant mesodermal region does not express ventrolateral genes early. This shows that neuroblasts do not require a wild-type ectodermal environment to differentiate and delaminate. Furthermore, as neuroblasts can delaminate in twist mutants, an underlying mesoderm is not required for their differentiation.

\section{Definition of the mesoderm boundaries}

The differences in the lateral boundaries of twist and snail expression domains might reflect the differences in the way the domains are set up. Although the boundary of twist initially appears to be determined by the maternal gradient of nuclear dorsal concentration alone, snail clearly requires twist activity to be expressed in the
Figure 7. Diagram summarizing early gene interactions in the mesoderm anlage. Black arrows represent maternal regulation of the early $t$ wist and snail transcription; white arrows represent the effects of zygotic genes on each other. Arrowheads denote activation; bars denote repression. (For further description and discussion of the model, see text.)
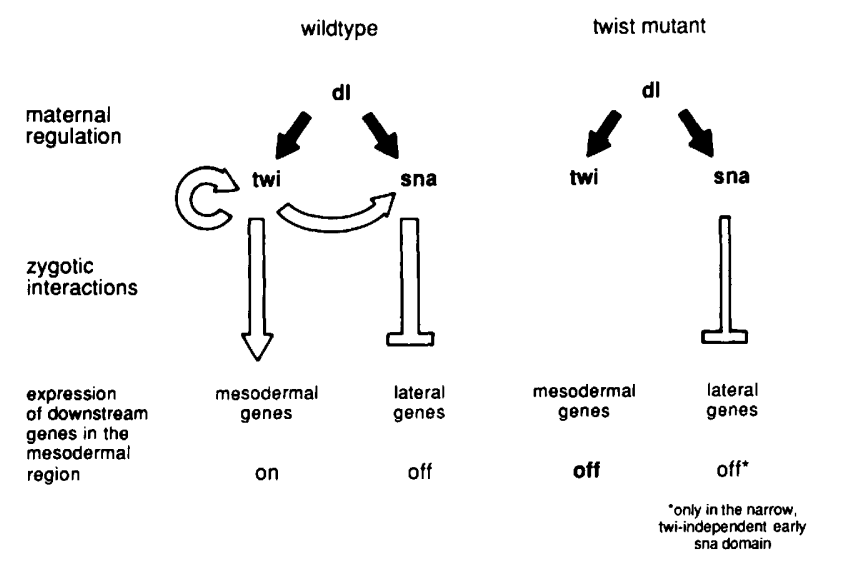
whole mesoderm. It is possible that twist responds to dorsal activity in a more or less linear way, whereas snail responds to a combination of dorsal and twist protein in a cooperative way, thus creating a sharper boundary. The late sharpening of the twist boundary might depend on a similar mechanism. Because twist is required for its own maintenance and dorsal protein persists well into germ-band extension, twist and dorsal too might interact to sharpen the twist boundary.

These data do not suggest any simple model to explain how the sim lines are made. In the absence of both twist and snail, sim is not expressed (Leptin and Grunewald 1990; Rushlow and Arora 1990), but the presence of either twist or snail alone allows the activation of sim. The ability of snail to activate sim expression (in twist mutants) seems to contradict its function as a repressor of $s i m$ in the mesoderm. Even in twist mutants, however, sim is off in the ventral-most band of cells and is only activated at the edge of the snail domain. Clearly, the precise position and width of the line is determined by $t$ wist and snail together.

Both twist and snail are initially activated in a narrow stripe. Assume that this expression is directly regulated by the maternal genes, because a zygotic gene required for the activation of twist and snail would have to be expressed (and its RNA translated into protein) before twist and snail. It is unlikely that such a gene exists, given the very early expression of twist and snail fonly two nuclear cycles or $20 \mathrm{~min}$ after syncytial blastoderm formation, when dorsal protein becomes differentially distributed). Furthermore, no other zygotic genes with phenotypes similar to $t w i s t$ and snail are known. This suggests that there are no zygotic genes acting upstream of twist and snail and that any other gene that might act in parallel to twist and snail cannot be absolutely required for the formation of the mesoderm. Thus, twist and snail might be the only genes at the top of the hierarchy of zygotic genes involved in mesoderm development. In this case, they would be sufficient for zygotic mesoderm determination, a hypothesis that might be tested by expressing them ectopically.

\section{Material and methods}

Fly stocks

Unless mentioned otherwise, the twist allele used was Df(2R)S60 (Simpson 1983) and snail was Df(2L)TE116GW11 (Ashburner et al. 1990). Both are complete null alleles, and no twist or snail RNA is produced, respectively. The twist snail double mutant was Df(2R)S 60 sna $a^{I I G}$, provided by K. Arora. The twist alleles used in the experiment in Figure 5 were $t w i^{I D}$, $t w i^{I I E}, t w i^{I I H}$, and $t w i^{D 5}$.

\section{Antibody staining and in situ hybridization}

Embryos from timed collections were dechorionated with bleach, fixed in $4 \%$ formaldehyde in PBS, and stained or hybridized (Tautz and Pfeifle 1989) as decribed previously (Leptin and Grunewald 1990). The snail antiserum (to be described in more detail elsewhere) was produced by immunizing rats with protein purified from bacteria expressing the full-length snail RNA (a gift from N. Brown) in the pET-3c expression vector. The serum was used at a dilution of $1: 30$.

\section{In situ hybridizations on frozen sections}

For hybridizations on frozen sections we used a protocol provided by Sommer and Tautz (1991), with slight modifications. Fixed and dechorionated embryos were oriented for transverse sectioning in OCT embedding medium, frozen, sectioned on a cryostat, and mounted on gelatin-coated microscope slides. The sections were refixed for $20 \mathrm{~min}$ in $4 \%$ formaldehyde in PBS, washed, in PBS and $0.1 \%$ Tween 20 , digested for $10 \mathrm{~min}$ in a drop of proteinase $\mathrm{K}(50 \mu \mathrm{g} / \mathrm{ml})$, washed, and fixed again for 20 min in $4 \%$ formaldehyde in PBS. They were hybridized overnight under a coverslip under the same conditions as for wholemount embryos and were also washed and stained in the same way as whole-mount embryos.

\section{Sections of stained embryos}

Stained embryos were dehydrated thoroughly, transferred to araldite, prepared for sectioning, and sectioned on a microtome (10- $\mu \mathrm{m}$ sections) as described previously (Leptin and Grunewald 19901.

\section{Acknowledgments}

I thank B. Grunewald for technical help, R. Sommer and D. Tautz for helpful suggestions on hybridizing frozen sections with digoxigenin probes, H. Jäckle, S. Roth, A. Alberga, N. Brown, S. Crews, E. Knust, and M. Noll for reagents. Gos Micklem made the in vitro snail protein for the production of antisera and many useful comments on the manuscript. I am also grateful to Jose Casal-Jimenez, Rolf Reuter, Siegfried Roth, Daniel St. Johnston, David Stott, Eric Weinberg, Rob White, and Michael Wilcox for suggestions and critical reading of the manuscript.

The publication costs of this article were defrayed in part by payment of page charges. This article must therefore be hereby marked "advertisement" in accordance with 18 USC section 1734 solely to indicate this fact.

\section{Note added in proof}

In contrast to the early mesodermal genes analyzed in this work, a recently described gene, $z$ fh- 1 , requires snail for its mesodermal expression (Lai et al. 1991. Mech. Dev. 34: 123-134). It will be interesting to see whether this is due to a direct positive regulatory effect of snail, or to repression of negative regulatory lateral genes, as discussed above.

\section{References}

Alberga, A., J-L. Boulay, E. Kempe, C. Dennefeld, and M. Haenlin. 1991. The snail gene required for mesoderm formation in Drosophila is expressed dynamically in derivatives of all three germ layers. Development 111: 983-992.

Ashburner, M., P. Thompson, J. Roote, P.F. Lasko, Y. Grau, M. El Messal, S. Roth, and P. Simpson. 1990. The genetics of a small autosomal region of Drosophila melanogaster containing the structural gene for alcohol dehydrogenase. VII. Characterisation of the region around the snail and cactus loci. Genetics 126: 679-694

Bodmer, R., L.Y. Jan, and Y.H. Jan. 1990. A new homeoboxcontaining gene, $m s h-2$, is transiently expressed early during 
mesoderm formation of Drosophila. Development 110: 661669.

Bogaert, T., N. Brown, and M. Wilcox. 1987. The Drosophila PS2 antigen is an invertebrate integrin that, like the fibronectin receptor, becomes localized to muscle attach ments. Cell 51: 929-940.

Bopp, D., E. Jamet, S. Baumgartner, M. Burri, and M. Noll. 1989. Isolation of two tissue-specific Drosophila paired box genes, Pox meso and POX neuro. EMBO I. 8: 3447-3457.

Boulay, J.L., C. Dennefeld, and A. Alberga. 1987. The Drosophila developmental gene snail encodes a protein with nucleic acid binding fingers. Nature 330: 395-398.

Campos-Ortega, J.A. and V. Hartenstein. 1985 . The embryonic development of Drosophila melanogaster. Springer-Verlag. Berlin/Heidelberg.

Crews, S.T., J.B. Thomas, and C.S. Goodman. 1988. The Drosophila single-minded gene encodes a nuclear protein with sequence similarity to the per gene product. Cell 52: 143-151.

Davis, R.L., H. Weintraub, and A.B. Lassar. 1987. Expression of a single transfected cDNA converts fibroblasts to myoblasts. Cell 60: 987-1000.

Edgar, B.A. and P.H. O'Farrell. 1989. Genetic control of cell division patterns in the Drosophila embryo. Cell 57: 177187.

Gould, A.P., J.J. Brookman, D.I. Strutt, and R.A.H. White. 1990. Targets of homeotic gene control in Drosophila. Nature 348: 308-312.

Grau, Y., C. Carteret, and P. Simpson. 1984. Mutations and chromosomal rearrangements affecting the expression of snail, a gene involved in embryonic patterning in Drosophila melanogaster. Genetics 108: 347-360.

Hopwood, N.D., A. Pluck, and J.B. Gurdon. 1989. A Xenopus mRNA related to Drosophila twist is expressed in response to induction in the mesoderm and the neural crest. Cell 59: 893-903.

Irish, V.F. and W.M. Gelbart. 1987. The decapentaplegic gene is required for dorsal-ventral patterning of the Drosophila embryo. Genes \& Dev 1: 868-879.

Kimble, M., R.W. Dettman, and E.C. Raff. 1990. The $\beta 3$-tubulin gene of Drosophila melanogaster is essential for viability and fertility. Genetics 126: 991-1005.

Knust, E., U. Dietrich, U. Tepass, K.A. Bremer, D. Weigel, H. Vässin, and J.A. Campos-Ortega. 1987. EGF homologous sequences encoded in the genome of Drosophila melanogaster, and their relation to neurogenic genes. $E M B O$ J. 6: 761-766.

Kosman, D., Y.T. Ip, M. Levine, and K. Arora. 1991. The establishment of the mesoderm-neuroectoderm boundary in the Drosophila embryo. Science (in press).

Leiss, D., U. Hinz, A. Gasch, R. Mertz, and R. Renkawitz-Pohl. 1988. $\beta 3$ tubulin expression characterizes the differentiating mesodermal germ layer during Drosophila embryogenesis. Development 104: 525-531.

Leptin, M. and B. Grunewald. 1990. Cell shape changes during gastrulation in Drosophila. Development 110: 73-84.

Michelson, A.M., S.M. Abmayr, M. Bate, A. Martinez Arias, and T. Maniatis. 1990. Expression of a MyoD family member prefigures muscle pattern in Drosophila embryos. Genes \& Dev. 4: 2086-2097.

Nambu, J.R., R.G. Franks, S. Hu, and S.T. Crews. 1990. The single-minded gene of Drosophila is required for the expression of genes important for the development of CNS midline cells. Cell 63: 63-75.

Nüsslein-Volhard, C., E. Wieschaus, and H. Kluding. 1984. Mutations affecting the pattern of the larval cuticle in Drosophila melanogaster. I. Zygotic loci on the second chromosome. Wilhelm Roux's Arch. Dev. Biol. 193: 267-282.
Paterson, B.M., U. Walldorf, J. Eldridge, A. Dübendorfer, M. Frasch, and W.J. Gehring. 1991. The Drosophila homologue of vertebrate myogenic determination genes encodes a transiently expressed nuclear protein marking primary myogenic cells. Proc. Nat. Acad. Sci. 88: 3782-3786.

Roth, S., D. Stein, and C. Nüsslein-Volhard. 1989. A gradient of nuclear localization of the dorsal protein determines dorsoventral pattern in the Drosophila embryo. Cell 59: 11891202.

Rushlow, C. and K. Arora. 1990. Dorsal ventral polarity and pattern formation in the Drosophila embryo. Sem. Cell Biol. 1: $137-149$.

Rushlow, C.A., K. Han, J.L. Manley, and M. Levine. 1989. The graded distribution of the dorsal morphogen is initiatied by selective nuclear transport in Drosophila. Cell 59: 11651177.

Simpson, P. 1983. Maternal-zygotic gene interactions during formation of the dorsoventral pattern in Drosophila embryos. Genetics 105: 615-632.

Slack, J. 1991. Embryology: Molecule of the moment. Nature 349: 16.

Sommer, R. and D. Tautz. 1991. Non-radioactive in situ hybridization to sectioned tissues. Trends Genet. 7: 110.

Steward, R. 1989. Relocalization of the dorsal protein from the cytoplasm to the nucleus correlates with its function. Cell 59: 1179-1188.

Tautz, D. and D. Pfeifle. 1989. A nonradioactive in situ hybridization method for the localization of specific RNAs in Drosophila embryos reveals a translational control of the segmentation gene hunchback. Chromosoma 98: 81-85.

Thisse, B., C. Stoetzel, T.C. Gorostiza, and F. Perrin-Schmitt. 1988. Sequence of the twist gene and nuclear localization of its protein in endomesodermal cells of early Drosophila embryos. EMBO I. 7: 2175-2183.

Tobin, S.J., P.J. Cook, and T.C. Burn. 1990. Transcripts of individual actin genes are differentially distributed during embryogenesis. Dev. Genet. 11: 15-26.

Vässin, H., K.A. Bremer, E. Knust, and J.A. Campos-Ortega. 1987. The neurogenic locus Delta of Drosophila melanogaster is expressed in neurogenic territories and encodes a putative transmembrane protein with EGF-like repeats. EMBO I. 6: 3431-3440.

Wolf, C., C. Thisse, C. Stoetzel, B. Thisse, P. Gerlinguer, and F. Perrin-Schmitt. 1991. The M-twist gene of mus is expressed in subsets of mesoderm cells and is closely related to the Xenopus X-twist and the Drosophila twist gene. Dev. Biol. 143: 363-373. 


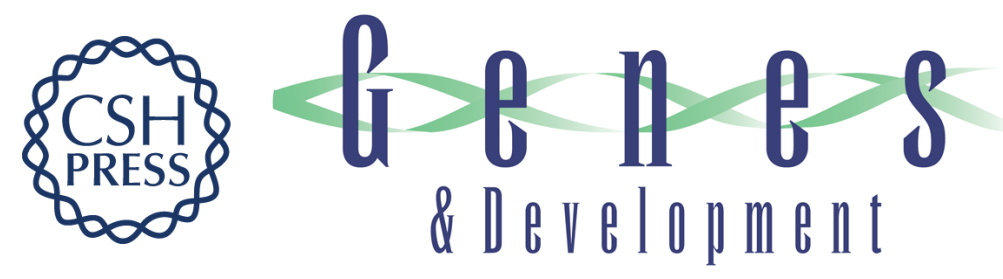

\title{
twist and snail as positive and negative regulators during Drosophila mesoderm development.
}

\author{
M Leptin
}

Genes Dev. 1991, 5:

Access the most recent version at doi:10.1101/gad.5.9.1568

$\begin{array}{ll}\text { References } & \begin{array}{l}\text { This article cites } 33 \text { articles, } 11 \text { of which can be accessed free at: } \\ \text { http://genesdev.cshlp.org/content/5/9/1568.full.html\#ref-list-1 }\end{array}\end{array}$

License

Email Alerting Receive free email alerts when new articles cite this article - sign up in the box at the top Service right corner of the article or click here.

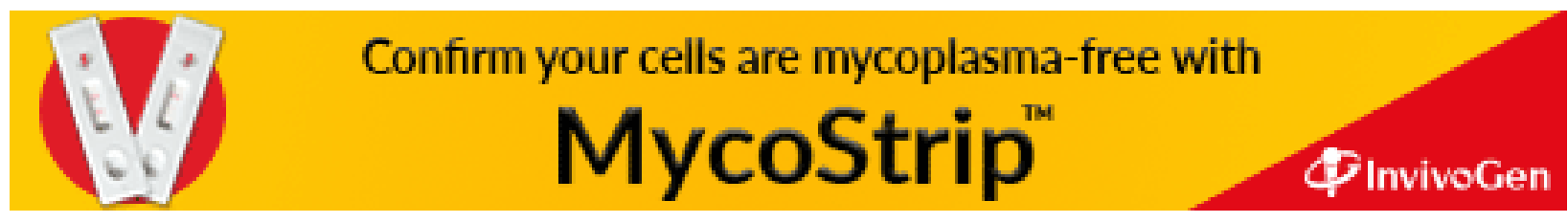

